\title{
A MICRO HISTÓRIA COMO APORTE TEÓRICO PARA OS ESTUDOS EM HISTÓRIA DA EDUCAÇÃO
}

\author{
MICROHISTORY AS A THEORETICAL CONTRIBUTION TO STUDIES IN THE HISTORY OF \\ EDUCATION
}

\section{LA MICRO HISTORIA COMO APORTE TEÓRICO PARA LOS ESTUDIOS EN HISTORIA DE LA EDUCACIÓN}

\section{Alexandre Ribeiro Neto ${ }^{1}$}

${ }^{1}$ Doutor em Educação pela UERJ. Docente do Departamento de Formação de Professores (Faculdade de Educação da Baixada Fluminense) da Universidade do Estado do Rio de Janeiro (UERJ), Duque de Caxias, RJ, Brasil.

Resumo: Intencionamos com o nosso texto contribuir com a reflexão sobre a produção do conhecimento no campo da História da Educação, apresentando a micro-história como aporte teórico metodológico possível para a leitura, questionamento e elaboração de hipóteses sobre as sociedades do passado, a partir de pistas, vestígios e sinais. Uma das dificuldades que o pesquisador da Educação encontra é que as fontes documentais de pesquisas, em alguns casos, possuem lacunas devido a perdas e a diferentes arranjos das instituições de memória. Como construir um modelo explicativo respeitando a singularidade do seu objeto de pesquisa? A partir do Paradigma Indiciário, proposto por Ginzburg (1989), apresentamos uma possibilidade de reunir as peças do quebracabeça e descobrir a beleza do desenho. Nosso texto apresenta o diálogo entre a História e a História da Educação. Elegemos como interlocutores Vainfas (2002), autor do livro Micro história: os protagonistas anônimos da História. Um dos primeiros estudos sobre o tema em tela. Espada Lima (2006) contribuiu para o debate sobre metodologia da pesquisa ao escrever o livro - A micro-história italiana: escalas, indícios e singularidades. Ele nos permite, compreender a gênese do movimento e os estudos desenvolvidos pelos diferentes autores. Schueler e Sooma (2008) publicaram uma resenha do livro de Espada Lima na Revista de História da Educação da Sociedade Brasileira de História da Educação, rompendo as fronteiras da História, aproximando o livro dos pesquisadores da História da Educação. Na mesma direção caminharam Faria Filho e Simões (2012). Eles publicaram no livro Pensadores Sociais e História da Educação, volume dois, um capítulo dedicado ao cruzamento do pensamento de Carlo Ginzburg e a História da Educação. Como resultado, nosso trabalho apresenta o debate sobre a utilização da micro-história como aporte teórico metodológico, para a pensar as pesquisas em História da Educação. Pretendemos caminhar numa trilha aberta pelos autores citados anteriormente, pensando os objetos de pesquisa, a metodologia e o uso das fontes documentais, para que tenhamos estudos que revelem novos matizes e nuances das sociedades do passado.

Palavras-Chaves: Micro-história; História da Educação; Fontes; Metodologia.

Abstract: Our aim, with this text, is to contribute to reflection on the production of knowledge in the field of History of Education, presenting Microhistory as a possible theoretical methodological contribution for reading, questioning and elaborating hypotheses about past societies, based on clues, traces and signs. One of the difficulties the researcher encounters is that there are sometimes 
gaps in the documentary sources, due to losses and different arrangements of memory institutions. How can we construct an explanatory model that respects the uniqueness of its research object? Based on the Evidence Paradigm, proposed by Ginzburg (1989) we present an alternative way to gather the pieces of the puzzle and discover the beauty of drawing. Our paper presents the dialogue between History and History of Education. We choose the following as interlocutors: Vainfas (2002), author of the book Micro história: os protagonistas anônimos da História [Microhistory story: the anonymous protagonists of History], one of the first studies on the subject on screen. Espada Lima (2006) contributed to the debate on methodology of research through his book $A$ micro história italiana: escalas, indícios e singularidades, which allows us to understand the genesis of the movement and the studies developed by different authors. Schueler and Sooma (2008) published a review of the book by Espada Lima in the Revista de História da Educação of the Brazilian History of Education Society - SBHE, breaking the frontiers of History and bringing the book closer to researchers in History of Education. Along similar lines is the work of Faria Filho and Simões (2012); in their book Pensadores Sociais e História da Educação, volume dois, there is a chapter dedicated to the intersection of Carlo Ginzburg's thought with History of Education. As a result, our work presents the debate on the use of Micro history as a theoretical methodological contribution, to reflect on research in History of Education. We intend to walk along the trail blazed by the abovementioned authors, thinking about the objects of research, the methodology, and the use of documentary sources, in order to promote studies that will reveal new nuances of societies of the past.

Keywords: Microhistory; History of Education; Sources; Methodology.

Resumen: Intencionamos con nuestro texto contribuir, con la reflexión sobre la producción del conocimiento en el campo de la Historia de la Educación, presentando la Micro historia como aporte teórico metodológico posible, para la lectura, cuestionamiento y elaboración de hipótesis sobre las sociedades del pasado, a partir de pistas, vestigios y señales. Una de las dificultades, que el investigador de la Educación encuentra es que las fuentes documentales de investigaciones, en algunos casos, poseen lagunas debido a pérdidas y a los diferentes arreglos de las instituciones de memoria. ¿Cómo construir un modelo explicativo respetando la singularidad de su objeto de investigación? A partir del Paradigma Indicio, propuesto por Ginzburg (1989), presentamos una posibilidad de reunir las piezas del rompecabezas y descubrir la belleza del diseño. Nuestro texto presenta el diálogo entre la Historia y la Historia de la Educación. Elegimos como interlocutores Vainfas (2002) autor del libro Micro historia: los protagonistas anónimos de la Historia. Uno de los primeros estudios sobre el tema. Espada Lima (2006) contribuyó al debate sobre metodología de la investigación al escribir el libro - La micro historia italiana: escalas, indicios y singularidades. Él nos permite, comprender la génesis del movimiento y los estudios desarrollados por los diferentes autores. Schuler y Sooma (2008) publicaron una reseña del libro de Espada Lima en la Revista de Historia de la Educación de la Sociedad Brasileña de Historia de la Educación, rompiendo las fronteras de la Historia, aproximando el libro de los investigadores de la Historia de la Educación. En la misma dirección caminaron Faria Filho y Simões (2012). Que publicaron en el libro Pensadores Sociales e Historia de la Educación, volumen dos, un capítulo dedicado al cruce del pensamiento de Carlo Ginzburg y la Historia de la Educación. Como resultado nuestro trabajo presenta el debate sobre la utilización de la Micro historia como aporte teórico metodológico, para pensar las investigaciones en Historia de la Educación. Pretendemos caminar por un sendero abierto por los autores citados arriba, pensando los objetos de investigación, la metodología yel uso de las fuentes documentales. Para que tengamos estudios, que revelen nuevos matices y matices de las sociedades del pasado. Palabras clave: Micro historia; Historia de la Educación; Fuentes; Metodología.

Era uma vez uma agulha, que disse a um novelo de linha: - Por que está você com esse ar, toda cheia de si, toda enrolada, para fingir que vale alguma cousa neste mundo? - Deixe-me, senhora. - Que a deixe? Que a deixe, por quê? Porque lhe digo que está com um ar insuportável? Repito que sim, e falarei sempre que me der na cabeça. - Que cabeça, senhora? A senhora não é alfinete, é agulha. Agulha não tem cabeça. Que lhe importa o meu ar? Cada qual tem o ar que Deus the deu. Importe-se com a sua vida e deixe a dos outros. - Mas 
você é orgulhosa. - Decerto que sou.- Mas por quê? -É boa! Porque coso. Então os vestidos e enfeites de nossa ama, quem é que os cose, senão eu? [...] Estavam nisto, quando a costureira chegou à casa da baronesa. Não sei se disse que isto se passava em casa de uma baronesa, que tinha a modista ao pé de si, para não andar atrás dela. Chegou a costureira, pegou do pano, pegou da agulha, pegou da linha, enfiou a linha na agulha, e entrou a coser. Uma e outra iam andando orgulhosas, pelo pano adiante, que era a melhor das sedas, entre os dedos da costureira, ágeis como os galgos de Diana — para dar a isto uma cor poética. (ASSIS, M. de).

\section{INTRODUÇÃOO}

Mais uma vez trazemos o Bruxo do Cosme Velho de volta à cena para começar a História. Procuramos muitas poesias para começar esse texto, lemos Drummond e também Cecília, porém não encontramos um texto que pudesse ser o fio inicial, levantando as questões que trataremos ao longo de todo o texto.

Os textos de Machado de Assis têm inspirando vários historiadores, entre eles a dupla Chalhoub e Pereira (1998). Logo a seguir em voo solo Chalhoub (2003), o último compêndio foi organizado pelo trio Chalhoub, Neves e Pereira (2005), com um capítulo do pesquisador John Gledson, que em suas publicações ao longo dos últimos dez anos nos brindam com novos matizes e nuances da sociedade dos Oitocentos. Contudo, nosso objetivo ao colocar essa epígrafe em nosso texto é diferente.

Intencionamos que o texto contribua com maior questionamento das fontes documentais de pesquisa em História da Educação. Em alguns casos as mesmas encontram-se dispersas, em várias instituições de memória. Logo, será preciso que o pesquisador monte um modelo explicativo, buscando em outros arquivos fontes do mesmo período e local, dados sobre a sociedade que ele deseja conhecer. Percorrendo assim os labirintos do passado, contando apenas com um único fio, que lhe indica inúmeras possibilidades.

A proposta é dialogar sobre o uso de fontes documentais de pesquisa em História da Educação, tomando como base os indícios, os vestígios, os sinais pouco perceptíveis aos olhos do pesquisador, que podem revelar áreas da produção cultural de agentes e sujeitos históricos, desprezados pela História Econômica e Política.

Nesse diálogo, elegemos como principais interlocutores os livros de: Vainfas (2002), Espada Lima (2006), Ginzburg (1987 e 2007) e outros. Há também o artigo publicado por Schueler e Sooma, na Revista de História da Educação, da Sociedade Brasileira de História da Educação em janeiro/abril, n. ${ }^{\circ} 16,2008$. Pensando a interface do pensamento de Carlo Ginzburg e a História da Educação, destacamos a contribuição de Faria Filho e Simões, no livro Pensadores Sociais e História da Educação, volume dois, publicado em 2012, no qual os autores propõe um diálogo entre História e a História da Educação.

\section{EsticANDO O FIO: A GÊNESE dO MOVIMENTO DA MiCRO-HISTÓRIA}

Os gregos contam que Teseu recebeu de presente de Ariadne um fio, com esse fio Teseu se orientou no labirinto, encontrou o Minotauro e o matou. Dos rastros que Teseu deixou ao vagar pelo labirinto, o mito não fala. [...]. Há figuras do passado que o tempo aproxima em vez de afastar. (GINZBURG, 2007, p. 7 e 53 ). 
Nessa seção pretendemos recuperar o início do movimento da micro-história, conhecendo suas preocupações inicias, os pesquisadores que participaram do mesmo e seus objetos de pesquisa. Tencionamos esticar o fio e da mesma forma que Teseu, entraremos no labirinto. O nosso fio é composto pelas diferentes contribuições de pesquisadores, que voltaram seus olhos para essa proposta metodológica, trazendo à luz seus conceitos, suas possibilidades e também seus limites. Para encontrar novamente a saída, seguiremos os nossos rastros, que são as leituras realizadas. Vasculharemos nos livros grifados a lápis, nas anotações feitas nas margens, para que as mesmas apontem a saída.

Há uma grande influência da historiografia francesa sobre os estudos históricos realizados no Brasil. A produção das sucessivas gerações do Movimento dos Annales apresenta proximidades e distanciamentos na forma de elaborar suas pesquisas, estabelecer suas hipóteses e coletar as fontes documentais. Contudo, uma leitura rápida pode nos levar a cometer equívocos e não perceber as matrizes disciplinares, com as quais cada geração do movimento de renovação da historiografia francesa dialoga.

Ronaldo Vainfas e Ciro F. Cardoso organizaram o livro - Domínios da História: ensaios de teoria e método, publicado em 2011. Nele, os organizadores e outros historiadores discutem seus objetos de pesquisa e a interface, com o movimento de renovação da historiografia francesa. Esse livro se transformou num marco do fazer historiográfico, orientando os iniciantes dos domínios de Clio. Nesse livro, o professor Ronaldo Vainfas discute a tendência historiográfica conhecida no Brasil como História das Mentalidades.

A proximidade entre a micro-história e a História das Mentalidades permitiu que alguns pesquisadores pensassem que uma era sinônimo da outra. Não é o que ocorre. Em outro livro, publicado em 2002, Ronaldo Vainfas, num dos primeiros a escrever um ensaio no Brasil sobre a micro-história, buscou desfazer esse equívoco.

Seja como for, a história das mentalidades que passou a reinar na historiografia francesa desde fins da década de 1960 tem sido caracterizada, precipitadamente, em função de seus temas e de seu estilo. [...] Quanto ao estilo, costuma-se realçar seu apego à narrativa e à descrição em detrimento da explicação globalizante. A adoção de recortes histórico-antropológicos e o apego à narrativa constituem, aparentemente, pontos de aproximação entre a micro-história e a história das mentalidades. E sem dúvida o são, no sentido em que ambas tendem a eleger objetos pouco ou nada frequentados pela historiografia geral sobre países, espaços geográficos e grandes estruturas socioeconômicas ou políticas, além de preferirem "contar a história", valorizar enredos e personagens muitas vezes anônimos. Mas esses pontos de aproximação não constituem, como veremos adiante, razões suficientes para dizer que uma é sinônimo da outra. (VAINFAS, 2002, p. 23-4).

Henrique Espada Lima nos ajuda a conhecer alguns equívocos cometidos por pesquisadores que, indevidamente, associavam à micro-história a diferentes trabalhos, e também como sinônimo de Nova História Cultural.

Microstoria - ou "micro-história" como foi traduzida - tornou-se nos últimos anos, uma das etiquetas mais difundidas com que se tentou catalogar esse debate historiográfico. O termo passou a ser referência comum par designar qualquer trabalho envolvendo análises históricas circunscritas e, seguidamente, até como sinônimo para os estudos da chamada "nova história cultural". Sua disseminação parece ter feito com que tomasse, muitas vezes, tantos sentidos que acabou por não recortar, senão apenas de modo muito ambíguo, uma perspectiva historiográfica particular. (ESPADA LIMA, 2006, p.14). 
O livro de Henrique Espada Lima, embora publicado em 2006, ficou algum tempo na penumbra. Talvez possamos creditar esse fato a leituras dos manuais mais consagrados, entre eles o livro Escola dos Annales 1929 -1989: a revolução francesa da historiografia, publicado em 1991. Todavia, no livro A escrita da História: novas perspectivas, publicado em 1992, organizado pelo autor, dedica um capítulo a micro- história, quem o escreve é Giovanni Levi. Mais uma vez, voltando os olhos para a produção de Peter Burke, que circula impressa na forma de livro, encontramos O que é História Cultural?, publicado em 2005. Nesse compêndio, também encontramos um capítulo dedicado à micro-história, $A$ vez da Antropologia Histórica, escrito pelo próprio Burke.

Alessandra Schueler e José Cláudio Sooma publicaram uma resenha sobre o livro de Henrique Espada Lima, na Revista Brasileira de História da Educação ${ }^{1}$. Os autores traziam à baila a contribuição do autor para o campo da historiografia. Seu livro representava uma possibilidade de aprofundar a discussão sobre a micro-história, buscando compreender a produção do grupo de historiadores, alguns desconhecidos do público brasileiro. Esse desconhecimento se deve, entre outros fatores, à ausência de tradução de seus textos para o português.

Voltemos ao texto de Henrique Espada Lima para compreender as proposições iniciais do movimento.

A micro-história foi formulada, nos seus princípios, como um conjunto de proposições e questionamentos sobre os métodos e os procedimentos da história social, articulando discussões esparsas em torno da relação da história com as outras ciências sociais - em especial a economia, a demografia e a antropologia. Um tecido de diálogo amplo e multifacetado que, em suas várias vertentes, era influenciado por proposições tão diversas quanto a historiografia francesa ligada a revista Annales, a história social britânica, as tradições marxistas e socialistas italianas ou a antropologia social. Os termos do debate, após seus primeiros passos, passaram a agregar um espectro variado de temas e questões. Isso desde a crítica às noções globalizantes e abstratas da historiografia tradicional - chamando a atenção para a necessidade de redução da escala de análise, para as discrepâncias e ambiguidades dos contextos estudados pelos historiadores - até a reproposição do papel dos agentes históricos individuais, e o esforço de pensar um paradigma para a história por meio do método "indiciário". (ESPADA LIMA, 2006, p. 16).

Henrique Espada Lima apresenta inicialmente a micro-história como um conjunto de questionamentos dos métodos usados pelos historiadores. Giovanni Levi marca o início do debate nos anos de 1970 e 1980, nos quais os modelos de produção encontravam-se em crise. Ouçamos o autor:

Há algumas características distintas na micro-história que derivam daquele período nos anos 70 , quando se iniciou um debate político e cultural mais geral. Não há nada particularmente incomum nisso, pois os anos de 70 e 80 foram, em quase todo o mundo, anos de crise para a crença otimista prevalecente de que o mundo seria rápida e radicalmente transformado em linhas revolucionárias. [...] O aparato conceitual com que os cientistas sociais de todas as convicções interpretavam a mudança atual ou passada foi sobrecarregado por uma carga de positivismo herdado. Os prognósticos de comportamento social estavam se comprovando demonstravelmente errôneos e esta falência dos sistemas e paradigmas existentes requeria não tanto a construção de uma nova teoria social geral, mas uma completa revisão dos instrumentos de pesquisa atuais. (LEVI, 1992, p.134).

Henrique Espada Lima destaca a importância da Revista Quaderni Storici, que funcionava como lócus de debate, produção e divulgação das propostas de historiadores, que em seus trabalhos, a partir de fontes seriais, dialogando com outros ramos do conhecimento, sobretudo a antropologia, analisavam diferentes regiões italianas. 
O debate nasce a partir da metade da década de 1970 nas páginas dos Quaderni Storici. Esta demarcação temporal bastante imprecisa traduz bem, entretanto, as relações que seus próprios protagonistas têm com ela. De fato, parte dos objetivos deste capítulo é compreender como um conjunto difuso de preocupações presentes em trabalhos diversos, de historiadores reunidos durante algum tempo em torno dessa revista, permitiu construir um dado quadro de problemas e referências mais ou menos comuns que foram identificados como micro-história. (ESPADA LIMA, 2006, p. 25).

Carlo Ginzburg, um dos mais conhecidos historiadores italianos, que participou do movimento, contribui para o debate em tela, recuperando a origem do conceito. Seu texto é marcado pelas suas lembranças pessoais e também, por uma pesquisa, para elucidar os principais arcabouços teóricos, seu diálogo com outros ramos do conhecimento e a suas especificidades.

Creio que a primeira vez que ouvi falar de "micro-História" foi em 1977 ou 1978, da boca de Giovanni Levi. Acho que me apropriei dessa palavra nunca ouvida sem pedir elucidações sobre o seu significado literal: devo ter-me contentado, imagino, com a referência à escala reduzida da observação que o prefixo "micro" sugere. Lembro-mebem, noentanto, dequeasnossasconversas deentãofalavam de "micro-história" comoumaetiqueta colada numa caixa historiografia a ser preenchida. Alguns tempos depois, Giovanni Levi, Simona Cerutti e eu começamos a trabalhar numa coleção, publicada pela editora Einaudi, intitulada precisamente "MicroHistória". Saíram, a partir de então, uns vinte volumes, de autores italianos e estrangeiros; alguns dos títulos italianos foram traduzidos para várias línguas; chegaram até a falar de uma "escola micro-histórica italiana". Mas recentemente, graças a uma pequena pesquisa terminológica retrospectiva, descobri que essa palavra, que acreditávamos desprovida de conotações, já havia sido utilizada por outros. (GINZBRUG, 2007, p.250-51).

Na citação anterior, o autor também situa o início do movimento na década de 1970. Ao apresentar a sua conversa com Giovanni Levi, nos faz seu confidente, e passa narrar suas memórias, percorrendo novamente os caminhos das parcerias na produção de uma coleção, em que outros pesquisadores participaram com seus trabalhos. Chamamos a atenção do leitor para um ponto importante, na citação anterior, que ele sinaliza ser um erro chamar a micro-história de escola. Outro ponto que ele se dedica, mas não será perseguido por nós, é a pesquisa sobre os primeiros trabalhos que usaram o conceito micro-história em seus títulos, ou como aporte teórico. Na próxima sessão desse texto, voltaremos nossos olhos para um dos conceitos mais caros à micro-história, a redução de escala.

\section{O tRABALHO DA AGULHA NO TECIDO: O CONCEITO DE REDUÇÃO DE ESCALA}

Alguns historiadores, mesmo fora do movimento da micro-história, nos ajudam a compreender o conceito de redução de escala, entre eles chamamos a atenção para o texto de Jacques Revel, Micro-História, macro-história: o que as variações de escala ajudam a pensar em um mundo globalizado, publicado na Revista Brasileira de Educação, publicada em 2010.

[...]. Não, o que está em jogo na abordagem micro-histórica é a convicção de que a escolha de uma escala peculiar de observação fica associada a efeitos de conhecimentos específicos e que tal escolha pode ser posta a serviço de estratégias de conhecimento. Retomando uma metáfora que foi muito utilizada nos últimos anos, variar a focalização de um objeto não é unicamente aumentar ou diminuir seu tamanho no visor, e sim, modificar a sua forma e sua trama. Ou então, para lançar mão de outro sistema de referência que a mim pessoalmente me parece mais elucidativo - o cartográfico -, a escolha de uma ou outra escala de representação não equivale a representar em tamanhos diversos uma realidade constante, e sim a transformar o conteúdo da representação mediante a escolha do que é representável. (REVEL, 2010, p.438). 
Em 2012, no segundo volume dos Pensadores Sociais e História da Educação, José Gondra analisou a obra de Jacques Revel. Um dos itens passados em revista é a escala de observação. Vejamos o que ele diz:

Para Jacques Revel (1998), a escala resulta de uma escolha que funciona como uma espécie de bússola, orientando e fornecendo um norte para a pesquisa, uma vez que estabelece parâmetros a respeito do que pode ser visto pelo historiador, delineando, igualmente, o ângulo da visada. Afirma, igualmente, a necessidade da escolha da escala de observação como condição necessária para o conhecimento, visto que a definição de uma escala participa de modo incontornável da fabricação dos problemas de pesquisa e das possibilidades de torná-lo inteligível (GONDRA, 2012, 86).

Na citação anterior, a redução de escala opera como uma bússola, orientando o pesquisador na definição do objeto de pesquisa. No texto de Henrique Espada Lima, a redução de escala coloca em relevo problemas que não seriam observáveis de outro modo.

Areduçãodaescaladeanáliseeraconsideradacomoumaoperaçãoquepermitiriaaohistoriadorcolocaremrelevo aspectos do problema estudado, que não seriam observáveis de outro modo. (ESPADA LIMA, 2006, p. 260).

Se para José Gondra a redução de escala figura como uma bússola, Burke (2005) recorrer à outra figura de linguagem - o microscópio -, para explicar o quadro teórico dos autores, adotando a micro história como metodologia de pesquisa.

Em primeiro lugar, a micro-história foi uma reação contra um certo estilo de história social que seguia o modelo de história econômica, empregando métodos quantitativos e descrevendo tendências gerais, sem atribuirmuita importânciaà variedade ou especificidade dasculturas locais.Em segundolugar, amicro-históriafoiuma reação ao encontro com a antropologia. Os antropólogos ofereciam um modelo alternativo, a ampliação do estudo de caso onde havia espaço para a cultura, para a liberdade em relação ao determinismo social e econômico, e para os indivíduos, rostos na multidão. O microscópio era uma alternativa atraente para o telescópio, permitindo que as experiências concretas, individuais ou locais, reingressassem na história. (BURKE, 2005, p. 60-1).

Chamamos Jacques Revel de volta à cena, ele contribui para ampliação do debate ao propor que: Mas o que me parece interessante nele é a ideia de que uma outra história e possível a partir da escolha de um ponto de vista particular (REVEL.2010, p.435). Henrique Espada Lima, a partir da obra de Giovanni Levi, apresenta a história de uma pequena comunidade camponesa italiana, um exemplo de como os pesquisadores desse movimento se dedicaram ao estudo de fontes seriais, dialogaram com a demografia, economia e antropologia para compreender áreas pouco expressivas dentro da Itália.

O percurso de pesquisa de Levi durante a década de 1970 - onde amadureceu a proposta de uma abordagem microanalitica - foi reunindo em um volume único, publicado em livro em 1985. Centro e periferia di uno estato assoluto ("Centro e periferia de um estado absoluto"). Organiza, com pequenas alterações, cinco artigos publicados por Levi entre 1971 e 1978. Lidos em linha, dão a impressão de um percurso natural marcado pela redução sucessiva da escala de análise - desde uma indagação macrodemográfica sobre a formação da população da cidade de Turim, passando pelo estudo de uma pequena região do Estado de Savóia, até a indagação sobre uma comunidade e o estudo de percursos individuais. (ESPADA LIMA, 2006, p.233).

Recorremos a Espada Lima para conhecer as fontes usadas por Giovanni Levi para o estudo demográfico da cidade de Turim.

As fontes utilizadas para lidar como problema são marcadamente seriais: para Turim, os recenseamentos, para outras duas cidades (Mondovi e Asti), os registros paroquiais (nesse caso, a origem declarada dos esposos do sexo masculino no momento do casamento) entre 1539 e 1729 . Por meio do levantamento extensivo desses registros Levi montava um quadro comparativo dos movimentos da população de duas cidades naquele período, comparando-os com a capital. (ESPADA LIMA, 2006, 235). 
Nas fontes seriais, Giovanni Levi poderia conhecer o que se repetia, o que mudava e também qual era o ritmo dessa mudança. O historiador, ao observar as regularidades e descontinuidades, propõe uma nova interpretação, sobre a relação campo e cidade. Vejamos quais eram as suas hipóteses.

Levi construía uma hipótese sobre a mobilidade populacional anterior ao nascimento do capitalismo. Uma mobilidade marcada por uma forte ligação entre centro e periferia, entre a vida da cidade e a vida no campo, que mantinham entre si um fluxo contínuo de população, composto de profissionais e até mesmo de mendigos (em idade ou condições menos profissionais). A referência às comunidades rurais é colocada aqui a serviço da interpretação da cidade, mas Levi apontava a necessidade de fazer o caminho inverso para compreender melhor o lugar das economias familiares locais na determinação desse processo, estudando de perto as comunidades camponesas (ESPADA LIMA, 2006, p.237-8).

Quando nomeamos essa sessão do trabalho da agulha no tecido, o fizemos pensando no tecido como aquilo que se pretende estudar, e a agulha como o instrumento analítico, que nos permite conhecer a realidade. No texto de Machado de Assis a discussão entre a linha e a agulha tomou conta do quarto de costura. Uma agulha não pode costurar sem linha, e o mesmo se pode dizer da linha, que não pode perfurar o tecido sem agulha.

O tecido sim, este pode tomar diferentes formas, dependendo dos instrumentos que usamos, da nossa intenção e do corte que fazemos nele. Nosso trabalho de pesquisador deve unir erudição na interpretação, criatividade para estabelecer os cortes cronológicos, dando ao objeto de pesquisa originalidade. Contudo, sem aportes teóricos metodológicos precisos, não conseguiremos montar um modelo explicativo das sociedades do passado. Na próxima sessão desse texto, analisaremos como Carlo Ginzburg pensou seus objetos de pesquisa, unindo criatividade e teoria.

\section{A costureira pegou o pano, pegou linha, pegou a agulha: Carlo GINZBURG O MICRO-HISTORIADOR}

O grupo de historiadores dedicados à micro-história originalmente era composto inicialmente por: Carlo Poni, Edoardo Grendi, Giovanni Levi e Carlo Ginzburg. Outros historiadores, mesmo fora da Itália, adotaram essa opção metodológica. As pesquisas conduzidas por Natalie Z. Davis mostram a forte influência dessa tendência historiográfica em seus textos.

Contudo, a maior parte dos livros publicados pelo grupo continuou por muito tempo esquecida. Recentemente, alguns pesquisadores tiveram maior penetração no meio acadêmico com Espada Lima (2006). Giovanni Levi, Herança Imaterial, publicada pela Einaudi em 1985. Natalie Z. Davis possui obras traduzidas para o nosso idioma. Entre sua vasta produção, citamos as obras - Nas margens: três mulheres do século XVIII, publicado pela Companhia das Letras em 199, e também Histórias de perdão: e seus narradores do século XVI, publicada pela mesma editora em 2001. Seus textos circulam razoavelmente, integrando as referências bibliográficas de estudos realizados por historiadores brasileiros.

A entrada de Carlo Ginzburg no movimento se dá nos anos de 1970. Ele é o que maior 
penetração alcançou. Seus livros são publicados no Brasil na década seguinte. O primeiro livro: O queijo e os vermes: o cotidiano e as ideias de um moleiro perseguido pela Inquisição foi publicado em 1987. O segundo livro: Os andarilhos do bem: feitiçaria a cultos agrários nos séculos XVI e XVII foi publicado em 1988. O terceiro: Mitos, Emblemas, Sinais: morfologia e história foi publicado em 1989. O livro História Noturna: decifrando o Sabá, em 1991. Seus livros foram lançados pela Companhia das Letras e atualmente contam com versões de bolso, o que torna o custo mais barato e aumenta a possibilidade de acesso, de estudantes de diferentes cursos de graduação.

Cabe ressaltar que, embora o livro chegasse primeiro ao Brasil, O queijo e os vermes: o cotidiano e as ideias de um moleiro perseguido pela Inquisição não foi o primeiro ser escrito e publicado pelo autor. Os andarilhos do bem: feitiçaria a cultos agrários nos séculos XVI e XVII marca a estreia de Carlo Ginzburg como autor, apresentado o resultado de pesquisa realizada no ano de 1966. Os livros chegaram ao nosso mercado editorial na ordem inversa.

A obra de Ginzburg influenciou as pesquisas em história social, sobretudo aqueles que se dedicavam em compreender a religiosidade no período colonial, como os estudos sobre as Visitações do Santo Ofício². Na Educação, encontramos referências esparsas, alguns estudos sobre o cotidiano escolar também adotam seus livros como suporte teórico-metodológico.

Para não perdermos o fio, voltemos ao texto de Schueler e Sooma (2008), pois eles nos revelam que o objetivo da abordagem teórico dos autores italianos era:

Descentrarahistóriaitaliana, estudarolocal,oregional,onacionaletransnacional,comnovospersonagens,problemas
e métodos, numa visão mais atenta à heterogeneidade, às disputas e à diversidade de escalas de análise. O interesse
pelo local, pelas áreas circunscritas, envolvia a comparação com casos análogos: aqui já havia uma crítica ao tempo
longodeBraudel, propondo-searticularo tempolongoe ograndeespaçogeográficocomasdinâmicas do tempocurto
e dos eventos políticos mais próximos à intervenção dos sujeitos sociais. (SCHUELER; SOOMA, 2008, p.236-37)

O Paradigma Indiciário consiste em seguir pistas, pequenos fragmentos, vestígios e indícios, para recuperar a história de sociedades de tempos pretéritos. Ginzburg (1989) usou os livros lidos pelo moleiro Domenico Scandela, vulgo Mennocchio, para conhecer a origem de ideias tão distintas sobre a criação do mundo. As leituras foram descobertas durante o processo inquisitorial sofrido pelo mesmo. O moleiro as compartilhava com os outros membros da aldeia. Havia um estrato cultural que a Igreja reprimia, porém ele veio à tona quando o mesmo divulga suas ideias em praça pública. Para detê-lo, ela resolveu processá-lo.

Gostaríamos, é claro, de saber muitas outras coisas sobre Menocchio. Mas o que temos em mãos já nos permite reconstruir um fragmento do que se costuma denominar "cultura das classes subalternas" ou ainda" cultura popular" [...], todavia, o emprego do termo cultura para definir o conjunto de atitudes, crenças, códigos de comportamento próprios das classes subalternas num certo período histórico é relativamente tardio e foi emprestado da antropologia cultural. (GINZBURG, 1987. p.16).

Em recente publicação, os pesquisadores Luciano Mendes de Faria Filho e Regina Simões apresentam um diálogo possível da obra de Carlo Ginzburg com a História da Educação.

Nessa obra, como no resto da sua instigante produção, Ginzburg tem trazido para a pauta do debate historiográfico contemporâneo questões derivadas da possibilidade de compor outras narrativas da/na história, da pluralidade de fontes mobilizadas na operação historiográfica e do rigor flexível no método da investigação histórica. Dessa forma, em mitos, emblemas e sinais: morfologia e história (GINZBURG, 1986), ele discute o "paradigma indiciário", ressaltando o faro, o golpe de vista e a intuição que sustentam a formação 
de saberes indiciários constituídos entre pistas, indícios e sinais, por meio dos quais se tornam visíveis detalhes aparentemente negligenciáveis da realidade pesquisada. (FARIA FILHO; SIMÕES, 2012, 26p.).

Espada Lima (2006) nos apresenta a influência de March Bloch na composição do método de interpretação da História de Carlo Ginzburg. Podemos ressaltar que ambos sãos judeus. A Segunda Guerra Mundial interrompeu a caminhada de March Bloch. Ele se alistou no exército francês e lutou na resistência. Foi capturado e fuzilado pelos nazistas. Deixou um livro inacabado - Apologia da História ou Ofício do historiador, que foi terminado pelo seu amigo Lucien Febvre.

Já foi dito que, apesar da importância dos professores italianos - e principalmente de Cantimori - sobre a formação de Ginzburg, Bloch teria sido seu verdadeiro "pai espiritual". Não há de fato como negar que o fundador dos Annales foi, de muitos modos, um dos principais "mestres" que ensinaram a Ginzburg como conceber a história. Podemos pensar que a trajetória do historiador francês tinha qualidades que estimulavam em Ginzburg uma admiração que não se limitava ás suas qualidades intelectuais: Bloch era um judeu francês que além do trabalho histórico fino e erudito tornou-se também um lutador da Resistência francesa aos nazistas, que o fuzilaram em Lyon, em 1944. (ESPADA LIMA, 2006, p.290).

Sobre a influência intelectual de Bloch sobre Ginzburg, podemos dizer que não apenas a maneira de conceber a história, mas também os objetos de pesquisa, sobretudo o interesse pela religiosidade popular. Mais uma vez recorremos a Henrique Espada Lima, que ressalta a influência do livro Os reis Taumaturgos de March Bloch sobre o historiador italiano.

A recuperação de um objeto marginal para a história, elemento central da operação a que se lançara Bloch em Les Rois thaumaturges, parece ter deixado uma marca importante nas escolhas de Ginzburg. O livro sugeria, ou ao menos permiti justificar, a escolha de um tema então pouco frequentado (e até mesmo pouco "respeitável) como a feitiçaria, que Ginzburg passaria a estudar naqueles anos. ((ESPADA LIMA, 2006, p.290).

Faria Filho e Simões (2012) interrogaram a forma como o pensamento de Ginzburg tem circulado entre os pesquisadores da Educação na elaboração de seus objetos de pesquisa, ou mesmo se apropriado do seu eclético método de trabalho.

Se observarmos o que tem sido publicado nas principais revistas de educação do país e, de modo mais específico, nas quatro revistas de história da educação - História da Educação, Revista Brasileira de História da Educação, Cadernos de História da Educação e Revista do HISTEDBR on-line -, veremos que, apesar de se constituir num autor de grande sucesso editorial entre nós, a produção de Carlo Ginzburg não tem sido mobilizada fortemente nas pesquisas realizadas na área. Observa-se que, quando referenciado na bibliografia dos trabalhos publicados, a mobilização das suas ideias tende a aparecer de forma rarefeita e pontual. (FARIA FILHO; SIMÕES, 2012, 28p.).

Os autores na citação anterior tomaram como fonte de pesquisa os artigos publicados em Revistas de Educação. O quadro se modificaria se interrogássemos os anais dos principais congressos e seminários de Educação? Há trabalhos apresentados em congressos que, devido a razões que fogem a esse texto, não são publicados nessas grandes revistas. Eles anunciam em suas palavras-chaves e resumos o uso de conceitos que remetem à obra do autor em tela, tais como: vestígios, pistas e Paradigma Indiciário. Também não podemos ser seduzidos por resumos de anais de congressos, pois há trabalhos que prometem desenvolver pensamento de Carlo Ginzburg. Ao lermos o texto completo, encontramos passagens rápidas, pouco densas, que lembram um leve verniz sobre a madeira. 
No momento em que escrevemos esse texto, o carteiro acabou de entregar as Revistas Brasileiras de História da Educação, uma delas, para ser mais exata, a edição $\mathrm{n}^{\circ} 2$ de maio/ agosto de 2012, v.12, apresenta na sessão dedicada as resenhas o trabalho de Thiago Borges de Aguiar sobre o livro Investigando Piero de Carlo Ginzburg. Nessa resenha, o autor apresenta o livro e os possíveis diálogos com a História da Educação.

Vemos aqui como o Ginzburg investigador de Piero della Francesa é muito mias do que o historiador que estudou a vida de um moleiro perseguido pela inquisição ou que reuniu Morelli, Freud e Sherlock Holmes num único texto, como ele aparece nos estudos de história da educação. É alguém que nos mostra que a construção histórica passa por uma discussão sobre o lugar da prova diante de uma documentação escassa e da necessária interdisciplinaridade para a realização desse debate. (AGUIAR, 2012, p. 270).

O autor da citação propõe que os pesquisadores da Educação produzam seus textos dialogando com aportes teóricos de outras áreas do conhecimento. Faria Filho e Simões (2012) interrogaram também o Banco de Teses e Dissertações da CAPES, na busca por referência ao trabalho do historiador italiano em trabalhos na área da Educação. Vejamos os resultados.

Ao cruzarmos os descritores Carlo Ginzburg e História da Educação na consulta realizada ao Banco de Dissertações e Teses da CAPES, encontramos 34 trabalhos produzidos, todos eles no período compreendido entre 200 a 2010. Desses trabalhos 27 foram defendidos entre 2006 e 2010. A análise das informações contidas nos resumos dessas produções indica que o interesse pela teoria guinzburguiana tendeu a circunscrever-se ao "paradigma indiciário"e o conceito de "circularidade". Em 14 trabalhos, Ginzburg aparece como principal referência teórico-metodológico apontada nos resumos. Nos demais, encontram-se referenciados principalmente os historiadores Michel de Certeau e Roger Chartier, com sete referências cada um. Outros historiadores citados são: Jacques Le Goff, Marc Bloch e Robert Darnton. No campo da sociologia, destaca-se Bourdieu, com cinco citações. Na área da história da educação, aparecem citações pontuais de autores como Diana Vidal, Maria Lucia Hilsdorf, João Silvério Bia Horta e Luciano Mendes de Faria Filho. Entretanto, nem sempre há indicações da maneira como se deu a articulação entre os autores de referência. (FARIA FILHO; SIMÕES, 2012, 29p.).

Uma possibilidade de entendimento do resultado encontrado pelos autores é pensar o intervalo de tempo pesquisado por eles. Os trabalhos que apresentam em seus descritores Carlo Ginzburg foram defendidos entre 2006 e 2010. Talvez isso esteja sinalizando que eles sejam fruto de uma geração que entrou em contato com o autor durante o curso de graduação. Esses pesquisadores, agora em seus trabalhos de mestrado e doutorado, em suas leituras teóricas incluíram a proposta metodológica de Carlo Ginzburg em suas pesquisas.

Faria Filho e Simões (2012) levantam como hipótese que o pensamento de Carlo Ginzburg pode ter percorrido caminho semelhante ao do pensamento do sociólogo Pierre Bourdieu em trabalhos na área da Educação. Ou seja, de maneira Incidental, de forma Conceitual Tópica, ou a apropriação do Modo de Trabalho. Os autores apresentam essa suposição baseados nos trabalhos de Afrânio Mendes Catani, Denice Bárbara Catani e Gilson R. de M. Pereira sobre a o pensamento do sociólogo francês. Contudo, os autores sinalizam que:

Por não termos realizado um estudo sistemático da apropriação do pensamento de Carlo Ginzburg na pesquisa em História da Educação, não é possível afirmar, com certeza, que sua apropriação no Brasil tenha acontecido de modo semelhante à apropriação feita do pensamento de Pierre Bourdieu, ou seja, muito mais de uma forma incidental do que uma apropriação do modo de trabalho, conforme argumentam os autores citados anteriormente. (FARIA FILHO; SIMÕES, 2012, 30p.). 
Faria Filho e Simões (2012) creditam essa ausência de pesquisas que se apropriem do modo de trabalho de Ginzburg, devido à sua difícil operação.

Dessa forma, a sedução dá lugar, igualmente, a uma enorme dificuldade de operacionalização do seu modo de trabalho, uma vez que para operar a partir de rastros, sinais e pistas é preciso ter, sempre e ao mesmo tempo, um amplo conhecimento do assunto pesquisado e de suas relações com obras clássicas e contemporâneas. Ou seja, se, como se confirmava recentemente Giovanni Levi na $34^{\mathrm{a}}$ International Standing Conference for the History of Education (San Luis de Potosi/México-2011), a Micro-História não se preocupa em fazer uma história do micro, ma simem elaborar perguntas gerais que possam ser respondidas em investigações locais, para fazeresse movimento torna-se necessário que o historiador possua a maestria e a erudição exigidas para a sua realização. Aqui, definitivamente, não bastam criatividade e boa vontade! (FARIA FILHO; SIMÕES, 2012, 30-1 p.).

O texto de Alessandra Schueler e Rebeca Natasha de Oliveira Pinto está presente nos anais do IX Seminário Nacional de Estudos e Pesquisa "História, Sociedade e Educação no Brasil, realizado pelo HISTEDBR, na Universidade Federal da Paraíba em julho/agosto de 2012, intitulado Intelectuais Negros e Reformas sociais: pensamento e projetos educacionais do professor André Pinto. O mesmo apresenta como aportes teóricos metodológicos os textos Giovanni Levi e Carlo Ginzburg e outros autores para iluminar o estudo de biografias e trajetórias de vida.

Estudar biografias e trajetórias de vida implica também reconstruir, trazendo à tona a percepção de Pierre Bourdieu, a " estrutura da rede" na qual este indivíduo está inserido e age. Isso nos ajuda a nos manter alerta, do ponto de vista teórico-metodologico, para os perigos e as armadilhas da "ilusão biográfica". [...] Nesse víeis Giovanni Levi defende que a narrativa biográfica seja analisada de forma "mais indireta do que direta", pois "trata-se de um meio eficaz de construir uma narrativa que dê conta dos elementos contraditórios que constituem a identidade de um indivíduo e das diferentes representações que dele se possa ter conforme os pontos de vista e as épocas (LEVI, 1996, p.170). Carlo Ginzburg também nos ajuda a pensar o estudo de biografias, afirmando que o olhar para estas construções narrativas deve ser no sentido de reconstrução dos contextos móveis compreendendoos como "campo de possibilidades historicamente delimitadas". (GINZBURG, 1989, p.183).

\section{Considerações Finais}

O início do debate sobre a micro história ocorreu nos anos de 1970 e 1980. Esses anos são marcados pela crise nos modelos de produção do conhecimento nas Ciências Humanas. A revista Quaderni Storici funcionou como lócus de debate, produção e divulgação das propostas dos historiadores dedicados a essa tendência historiográfica.

O grupo de historiadores dedicados à micro história originalmente era composto inicialmente por: Carlo Poni, Edoardo Grendi, Giovanni Levi e Carlo Ginzburg. Outros historiadores, mesmo fora da Itália, adotaram essa opção metodológica. As pesquisas conduzidas por Natalie Z. Davis mostram a forte influência dessa tendência historiográfica em seus textos. Do núcleo italiano, no Brasil o mais conhecido é o historiador Carlo Ginzburg.

Micro-história não é sinônimo de História das Mentalidades, embora dela se aproxime ao valorizar enredos e personagens anônimos. Micro-história também não é sinônimo de Nova História Cultural. Embora valorize a narrativa, ela possui contornos particulares, entre eles o diálogo e a demografia. A redução de escala é um dos principais conceitos, que ajuda a compreendê-la, pois ela coloca em relevo problemas que não seriam observáveis de outro modo. 
Não somos e nem queremos ser a última palavra sobre a micro-história, pretendemos abrir um caminho profícuo de pensar os objetos de pesquisa, o uso das fontes documentais de pesquisa e a metodologia, para que tenhamos estudos que revelem novos matizes e nuances das sociedades do passado. Os trabalhos produzidos no campo da História da Educação podem ser valer de indícios, pistas e vestígios e revelar outras faces ainda desconhecidas dos processos de escolarização, trazendo à baila outros sujeitos, que na malha da História Geral foram silenciados e relegados ao anonimato.

\section{REFERÊNCIAS:}

AGUIAR, T. B. de. Investigando Piero. In: Revistas Brasileiras de História da Educação, v.12, n. ${ }^{\circ}$, maio/agosto de 2012 .

ASSIS, M. de. Um apólogo. Editora Ática, São Paulo, 1984. www.releituras.com/machadodeassis. Acessado em 21/12/2012.

BETHENCOURT, F. História das Inquisições: Portugal, Espanha e Itália. Portugal: Temas e Debates, 1996.

BURKE, P. O que é História Cultural? Rio de Janeiro: Jorge Zahar Editor, 2005.

CARDOSO, C. F.; VAINFAS, R. (Orgs.). Domínios da História: ensaios de teoria e metodologia. $2^{\text {a }}$ Ed. Rio de Janeiro: Elsevier, 2011.

ESPADA LIMA, H. A micro-História italiana: escalas, indícios e singularidades. Rio de Janeiro: Civilização Brasileira, 2006.

FARIA FILHO, L. M. de; SIMÕES, R. H. S. História e historiografia no pensamento de Carlo Ginzburg: tecendo diálogos com a pesquisa histórica em educação. In: LOPES, E. M. T.; FARIA FILHO, L. M. de (Orgs.). Pensadores Sociais e História da Educação, volume 2, Belo Horizonte: Autêntica, 2012.

GINZBURG, C. O queijo e os vermes: o cotidiano e as ideias de um moleiro perseguido pela Inquisição. São Paulo: Companhia das Letras, 1987.

GINZBURG, C. O fio e os rastros: verdadeiro, falso, fictício. São Paulo: Companhia das Letras, 2007.

GONDRA, J. G. Telescópio, microscópio, incertezas: Jacques Revel na história e na história da educação. In: LOPES, E. M. T.; FARIA FILHO, L. M. de (Orgs.). Pensadores Sociais e História da Educação, volume 2, Belo Horizonte: Autêntica, 2012.

REVEL, J. Micro-História, macro-história: o que as variações de escala ajudam a pensar em um mundo globalizado. In: Revista Brasileira de Educação, v. 15 n. 45 set. /dez. 2010. http://www.scielo.br/pdf/ rbedu/v15n45/03.pdf. Acessado em 16/12/2012.

SCHUELER, A. F. M. de; SOOMA, J. C. A micro-história italiana: escalas, indícios e singularidades. In: Revistas Brasileiras de História da Educação, n. ${ }^{\circ}$ 16, janeiro/abril, 2008.

SCHUELER, A. F. M. de; SOOMA, J. C.; PINTO, R. N. O. Intelectuais negros e reformas sociais: pensamento e projetos educacionais do professor André Pinto. In: IX Seminário Nacional de Estudos e Pesquisa" História, Sociedade e Educação no Brasil". Universidade Federal da Paraíba: João Pessoa, julho/agosto de 2012. Anais eletrônicos. http://www.histedbr9seminario.com.br/. Acessado em 09/11/2012.

VAINFAS, R. Micro-história: os protagonistas anônimos da História. Rio de Janeiro: Campus, 2002. 
Artigo recebido em: 27/08/2017

Aprovado em: 26/10/2017

Contato para correspondência:

Alexandre Ribeiro Neto.E-mail: aleribeironeto@gmail.com

NOTAS

1 Para ler a resenha na íntegra, consultar a Revista Brasileira de História da Educação. São Paulo: Autores Associados, janeiro/abril, n.016, 2008, p. 235-241.

2 Aos que desejarem conhecer detalhadamente a atuação da Inquisição, indicamos o livro de Francisco Bethencourt. História das Inquisições: Portugal, Espanha e Itália. Portugal: Temas e Debates, 1996. Nele o autor faz uma síntese da história da Igreja no período Moderno, sem se esquecer de citar trabalhos de autores brasileiros, com de Anita C. Novinsky e Daniela B. Calainho sobre os familiares do Santo Ofício. Atualmente o livro possui uma edição brasileira da Companhia das Letras. 